Suresh Sagadevan*, Selvaraj Vennila, Preeti Singh, Jayasingh Anita Lett, Mohd Rafie Johan, Ab Rahman Marlinda, Bavanilatha Muthiah and Muthukrishnan Lakshmipathy

\title{
Facile synthesis of silver nanoparticles using Averrhoa bilimbi $L$ and Plum extracts and investigation on the synergistic bioactivity using in vitro models
}

https://doi.org/10.1515/gps-2019-0058

Received March 10, 2019; accepted May 28, 2019.

\begin{abstract}
The bacterial communities (Gram-negative and Gram-positive) form the biofilms which oppose the mode of action of antibiotics and affecting the immune system of the human. These chronic infections related to biofilm are always hard to be cured because of their inherent resistance to both antimicrobial agents and host defense. The present study is devoted to the synthesis of silver nanoparticles (AgNPs) using aqueous extracts of Averrhoa bilimbi leaf and Plum fruit (Prunus bokharensis) and its inhibitory effect on Staphylococcus aureus, Escherichia coli, Pseudomonas aeruginosa, and Salmonella typhi. Here, AgNPs) were successfully prepared by green synthesis method obtained by the reduction of silver nitrate into silver ions. The synthesized AgNPs were characterized by UV-Vis Spectroscopy, XRD, FTIR, FESEM-EDAX and DLS analysis. The antimicrobial effects of the two extract were evaluated by the disk diffusion method. The green synthesized AgNPs exhibited good antibacterial activity against both Gram-negative and
\end{abstract}

\footnotetext{
* Corresponding authors: Suresh Sagadevan, Nanotechnology \& Catalysis Research Centre, University of Malaya, Kuala Lumpur 50603, Malaysia, e-mail: drsureshnano@gmail.com Mohd Rafie Johan and Ab Rahman Marlinda, Nanotechnology \& Catalysis Research Centre, University of Malaya, Kuala Lumpur 50603, Malaysia

Selvaraj Vennila, PG Research Department of Physics. Jayaraj Annapackiyam College For Women (Autonomous) Periyakulam - 625 605, Tamilnadu, India

Preeti Singh, Bio/Polymers Research Laboratory, Department of Chemistry, Jamia Millia Islamia, New Delhi - 110025, India Jayasingh Anita Lett, Department of Physics, Sathyabama Institute of Science and technology, Chennai - 600 119, India

Bavanilatha Muthiah, Faculty of Bio \& Chemical Engineering, Sathyabama Institute of Science and Technology (Deemed to be University), Rajiv Gandhi Salai, Chennai, Tamilnadu - 600 119, India Muthukrishnan Lakshmipathy, Leather Process Technology, Tannery Division, CSIR - Central Leather Research Institute (CLRI), Adyar, Chennai, Tamilnadu - 600 020, India
}

Gram-positive. They were also analyzed for their significant antibacterial activities against all the test cultures exposed whereas Escherichia coli and Salmonella typhi topped among other test cultures. The anti-proliferative activity of phytochemical mediated synthesis of Ag NPs was investigated for their cytotoxicity in Vero and Human epidermoid larynx carcinoma cell lines (HEp-2) based on their viability using MTT assay. The present study also represents the synergistic bioactivity of silver nanoparticles using in vitro models.

Keywords: silver nanoparticle; Averrhoa bilimbi; Prunus bokharensis; antimicrobial activity; MTT

\section{Introduction}

Antibiotics are promising candidate in the treatment of bacterial/microbial infection in humans. The existing role of medicine and their indescrimate use among human have resulted in the emergence of multidrug-resistant bacteria. But nowadays, due to the development of resistance of these micro-organisms against frequently use antibiotics these man-made synthetic antibacterial are not as much effective to act against bacteria. Development of drug-resistance among human is an immense challenge for pharmacist and researchers working on biomedicine due to fear of reemergence of bacterial infection [1,2]. As a result, a vast increase in the number of bacterial infections is observed mainly caused by microorganism growing in the form of biofilms. Gram-Positive and Gram-negative bacteria, both can form biofilms indwelling medical devices such as mechanical heart valves, prosthetic joints. Most commonly found biofilms formed by bacterial associates commonly with human diseases are Staphylococcus aureus, Escherichia coli, Pseudomonas aeruginosa, Salmonella typhi, Klebsiella pneumonia, Staphylococcus epidermis, Staphylococcus viridians, etc. [3,4]. Healing efficiency of antibiotics intimate directly with their bacteriostatic 
effects. Conversely, Bacteria can be adapted to the selective pressure from antibiotics via genetic adaptation foremost to the development of antibiotic resistance. But, at present efficiency of this conventional antibiotic treatments is declining, whereas the occurrence of multiple resistant pathogenic bacteria is increasing day by day. The antibacterial potential of plants extracts is anticipated to hindrance the process through the materialization of effective antimicrobial substances [5].

Nanotechnology is an enormous scientific advancement with profound implications in all the existing fields such as chemistry, biology, physics, material science, and engineering. The core of nanotechnology relies on the size, shape and opto-chemical properties in transforming a naive particle into a functional one [6]. There are two commonly known classical methods of synthesizing nanoparticles viz. chemical and physical method with certain limitations such as the cost, release of hazardous by-products, time-consuming and most importantly downstream processing of nanoparticles [7]. To overcome this scenario and to reduce the use of toxic and hazardous materials for synthesizing nanomaterials, green synthesis route has been employed actively across all fields of science and technology [8]. Biosynthesis of nanoparticles using bacteria, fungi, alga, and plant materials has been the most sought out alternative in material science for an eco-benign synthesis of nanomaterials [9].

Thus, Nanoparticle can also be synthesized by the biological technique which is a quite challenging concept known as "green synthesis" of the nanoparticle. Green or biological synthesis of the nanomaterial can resolve the environmental challenges such as solar energy conservation, agricultural production, catalysis [10] and biotechnological area [11]. The green synthesis method is cost-effective, easily available, eco-friendly, less toxic in nature, large-scale production and act as reducing and capping agent as compared to the chemical method which in comparison is very costly along with this it emits hazardous by-product which can have some venomous effect on the environment [12]. Green synthesis of nanoparticles utilizes naturally occupying reducing agent such as plant extract, microorganism, enzymes, a polysaccharide which are simple and viable can act as an alternative to the complex and toxic chemical processes helps to reduce the consequence of chemical methods [13]. Recently, plants and their product have been gaining importance due to their unique constituents and their versatile applicability in various developing fields of research and development for living and non-living. Plants provide a potential pathway provides a safe and beneficial way to the synthesis of the nanoparticle as compared to other existing different biological agents such as bacteria, fungi, etc. As the plants are easily accessible provides the possibilities for large-scale production and eco-friendly also [14]. Thus, Nanotechnology can be considered as an advanced and effective move toward the development of novel non-traditional antibacterial/microbial agents using plants products.

To exploit the constituents of plants various researchers have combined the research on plants with the well-established field of Nanoscience can be called as "Nanobiotechnology". In the current situation, the Nano-biotechnology is one among the most energetic platform, explore the contemporary substantial discipline where the plants and various plant products find an imperious use in the fabrication of nanoparticles [15]. As vast applications of Nanomaterials in various fields such as electronic, magnetic, optoelectronics, and information storage are well established. They are also broadly applied in shampoos, detergents, soaps, cosmetics, toothpaste, and medical and pharmaceutical product. Researchers have found the remarkable application of Nanomaterial in the field of medicine such as antimicrobial activity. The use of nanomaterials extends in the areas of cosmetics and healthcare products, in biomedicine and as a carrier in drug delivery, in chemical industries, in optics, electronics, space industries, energy science, catalysis, single electron transistors, light emitters, nonlinear optical devices, and photo-electrochemical applications and so on [16].

The metallic nanoparticles such as copper, zinc, titanium, magnesium, gold, etc. are considered the most promising due to their remarkable antimicrobial properties. This antimicrobial property attracts the interest of researchers due to the development of resistant strains of microbes against antibiotics. Compared to other heavy metal nanoparticles, silver nanoparticles are most important because of their unique properties such as good conductivity, chemical stability, catalytic and most important antibacterial, antiviral, antifungal and antiinflammatory activities. The green synthesis of silver nanoparticles (Ag NPs) has made a lot of mindfulness from scientific experts and analysts everywhere throughout the world. Especially, Indian greenery is yet to discover its inestimable resource of cost-effective, safe reducing and stabilizing compounds bestowed in the preparing of Ag NPs [17,18]. Silver nanoparticles have already been synthesized using various plant extracts such as Acorus calamus [19], Sesuvium portulacastrum [20], Ficus carica [21], etc. have already been reported earlier.

In our present study, we have applied the eco-friendly and convenient green method for the synthesis of silver nanoparticles from silver nitrateusing the A. bilimbileafand 
P. bokharensis (Plum) fruit extracts. In the research, the plant-mediated synthesized silver nanoparticles were characterized by structural, optical and chemical characterization techniques and studied in details with all of their significant properties. The antimicrobial effects of the plant extract were evaluated by the disk diffusion method. This work is the first reported study present on the synthesis of silver nanoparticles using Plum fruit extracts and $A$. bilimbi leaf extract which is an additional confirmation of previous reports on the biological synthesis of silver nanoparticles using A. bilimbi leaf [22] and their antimicrobial activity.

\section{Materials and methods}

\subsection{Plant collection and authentication}

The medicinal plant Averrhoa bilimbi is shown in Figure 1 and was collected from IIT-Madras campus, Guindy, Chennai, Tamil Nadu in a sterile polyethylene bag. Morphological characteristics of the selected plant were recorded, and it was authenticated by the Chief Botanist, Tamil Nadu Medical Plant Farms and Herbal Medicine Corporation Limited (TAMPCOL) at Government Siddha Medical College, Arumbakkam, Chennai, India. Similarly, fresh fruits of Prunus bokharensis (Plum) is shown in Figure 2 and were procured from the Koyambedu Market. The morphological characters were recorded and authenticated by the Chief Botanist, TAMPCOL.

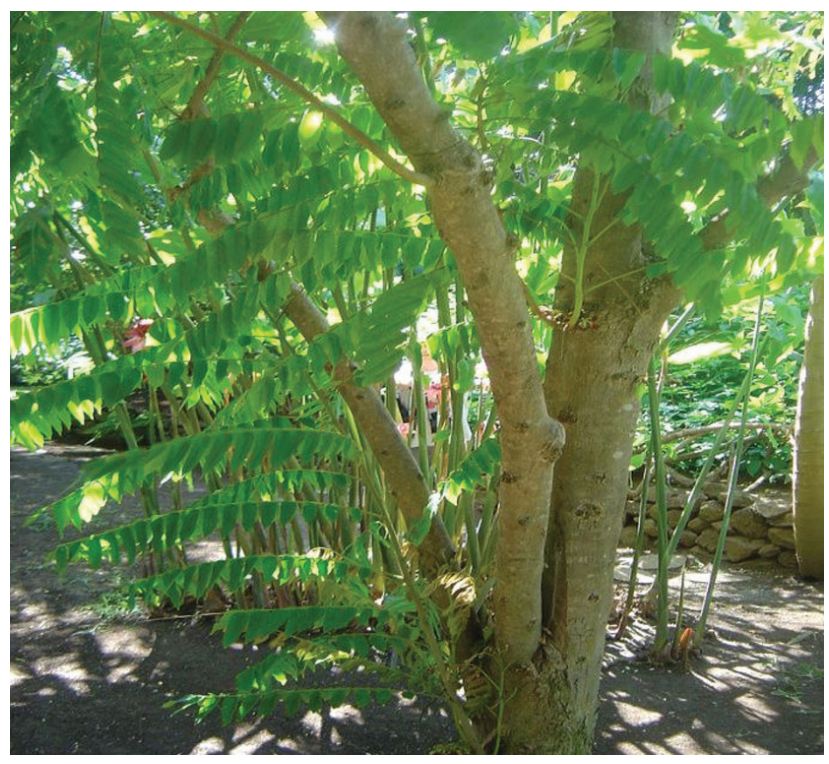

Figure 1: Averrhoa bilimbi.

\subsection{Preparation of extracts}

A. bilimbi leaves and P. bokharensis fruits collected were thoroughly washed in distilled water, chopped into fine pieces and left to dry at room temperature. $100 \mathrm{~g}$ of dried leaves of $A$. bilimbi was boiled in $100 \mathrm{~mL}$ of distilled water in a separate flask and filtered through Whatman No. 1 filter paper. The filtrate obtained was stored at $4^{\circ} \mathrm{C}$ for further experimental. The Plum fruits' seeds were blended with a mixer (50:50) to a paste-like consistency and filtered using a Whatman No.1 filter. The filtrate obtained was stored at $4^{\circ} \mathrm{C}$ for further experimental (Figure 3).

\subsection{Synthesis of silver nanoparticles}

\subsubsection{Averrhoa bilimbi leaf and Plum fruit extract}

The aqueous solution of $1 \mathrm{mM}$ silver nitrate $\left(\mathrm{AgNO}_{3}\right)$ was prepared and used for the synthesis of silver nanoparticles. To $10 \mathrm{~mL}$ of aqueous plant extract of Averrhoa bilimbi leaf and Plum fruit took in two separate Erlenmeyer flasks, $90 \mathrm{~mL}$ of $1 \mathrm{mM} \mathrm{AgNO}$ was added separately under the stirring condition and kept for $20 \mathrm{~min}$ at $60^{\circ} \mathrm{C}$.

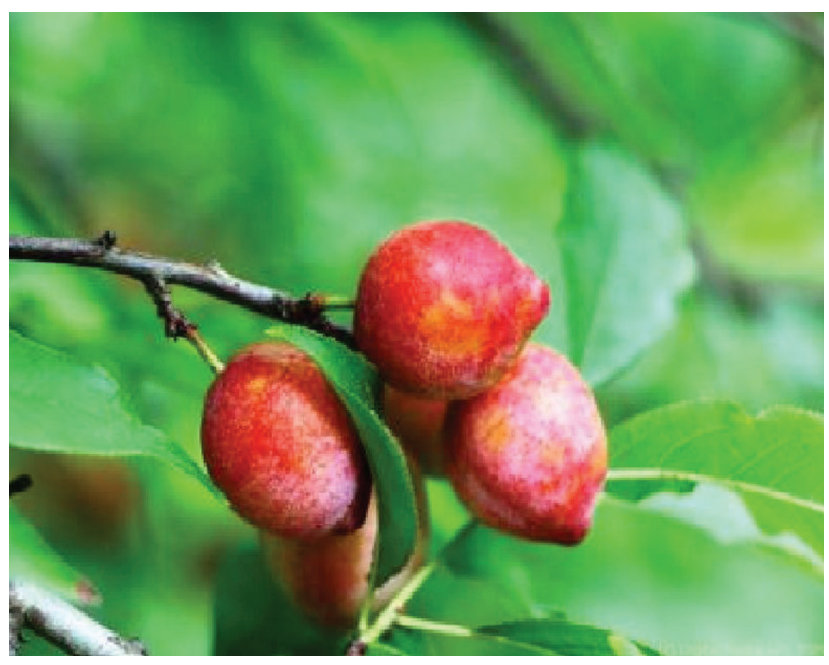

Figure 2: Prunus bokharensis (Plum).

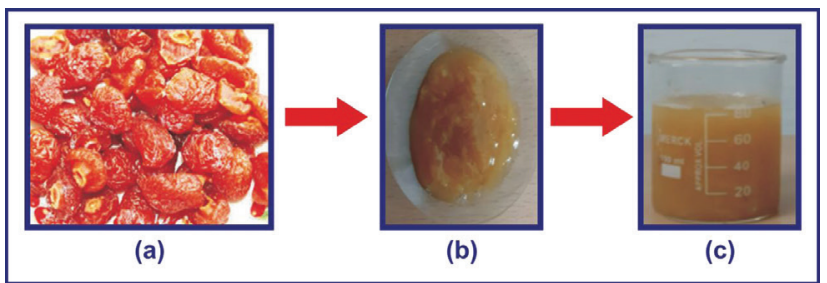

Figure 3: Formation of plant extract of Plum fruit: (a) dried seeds, (b) organic extract, (c) filtered solution (fruit extract). 
The presentation color of the mixture in two separate flasks was observed for any color change upon reduction [23].

\subsection{Characterization of silver nanoparticles}

Due to the reduction of $\mathrm{Ag}^{+}$ions, the visual change in color was observed upon heating and cultivation of the reaction mixture. UV-Vis Spectra (Shimadzu-1800) was measured in the range of $200-800 \mathrm{~nm}$. The X-ray diffractometer (XPERT-PRO) using $\mathrm{Cu}-\mathrm{K} \alpha$ radiation of wavelength $\lambda=1.541$ $\AA$ A was used to find the crystallite size and phase purity. The FTIR spectra were recorded using JASCO FT/IR 4600 in the range of $4000-400 \mathrm{~cm}^{-1}$ to confirm the functional groups present. The surface morphology was analyzed by Field emission scanning electron microscopy (FESEM, Supra55, India) and the elemental composition identification was recorded using EDX, BRUKER, India. Dynamic light scattering (DLS was employed to study the average particle size by DelsaNano C instrument (Beckman Coulter).

\subsection{In vitro cytotoxicity study}

\subsubsection{Cell line maintenance and growth conditions}

Vero (African green monkey kidney epithelial cells) and Hep-2 (Human epidermoid larynx carcinoma) cell lines were procured from NCCS, Pune, India. Cells were examined for confluency and contamination and retained for further experimental by incubating at $37^{\circ} \mathrm{C}$ with $5 \% \mathrm{CO}_{2}$.

\subsubsection{Cytotoxicity assay - MTT method}

Vero and HEp-2 cells were cultured in 96 well microplates $\left(1 \times 10^{5}\right.$ cells/well) in 10\% FBS incorporated DMEM medium for $18 \mathrm{~h}$ and then incubated with different concentrations of samples (500, 250, 125, 62.5, 31.25, $15.625 \mu \mathrm{g} / \mathrm{mL})$. The control well was made with cells inoculated in $100 \mathrm{~mL}$ of the medium. The plate was incubated at $37^{\circ} \mathrm{C}$ in a $\mathrm{CO}_{2}$ incubator for $24 \mathrm{~h}$. After incubation $10 \mu \mathrm{L}$ of MTT $(5 \mathrm{mg} / \mathrm{mL})$ solution was added to each well and incubated for $4 \mathrm{~h}$. The formazan crystals formed was solubilized in $100 \mu \mathrm{L}$ of DMSO and the OD was recorded at $540 \mathrm{~nm}$ in an ELISA plate reader. The \% viability of cells was calculated using the formulae:

$$
\% \text { of Viability }=\frac{\text { Mean OD value of test sample (Agnps) }}{\text { Mean OD value of experimental control }}
$$$$
\times 100
$$

\subsubsection{Statistical analysis}

The experiment was performed in triplicates and all the data articulated as the mean \pm standard error of the mean. The outcomes were subjected to Student's $t$-test and calculated statistically significant if the $p$-value $\leq 0.05$.

\section{Results and discussion}

\subsection{Biosynthesis of silver nanoparticles}

The extract of Averrhoa bilimbi leaf and Plum fruit were mixed and incubated with $\mathrm{AgNO}_{3}$ solution, change in color of the solution from pale green to dark brown indicated the visible reduction of leaf and fruit extracts arbitrated synthesis of AgNPs. The reaction mixture of Plum fruit extract after 20 min of reaction is shown in Figure 4. The color change designated the transformation to AgNPs. Whereas when the two mixtures were heated separately at $60^{\circ} \mathrm{C}$ for $20 \mathrm{~min}$, the color change was more prominent than compared to change occurring at room temperature. After the heat treatment, the mixtures could cool normally at room temperature to complete the reduction process. It was observed that the reduction was completed within $24 \mathrm{~h}$ since no further color change was observed indicating the complete reduction to AgNPs. This reduction of the metal ions occurs fairly rapidly; more than $90 \%$ of reduction of $\mathrm{Ag}+$ ions completes within $10 \mathrm{~min}$ after the addition of the metal ions to plant extract. The expected color change in AgNPs in water is due to Surface Plasmon Resonance (SPR) $[24,25]$ arising due to the upward transition of free electrons in AgNPs giving rise to the SPR absorption band because of the resonance of AgNPs with the light wave [26]. Similar results have also been reported in Earlier studies on the synthesis of AgNPs synthesized by A. bilimbi leaf extract also report similar outcomes thus confirming the complete transformation of and $\mathrm{AgNO}_{3}$ to AgNPs using Averrhoa bilimbi leaf and Plum fruit extracts [22]. The metal particles

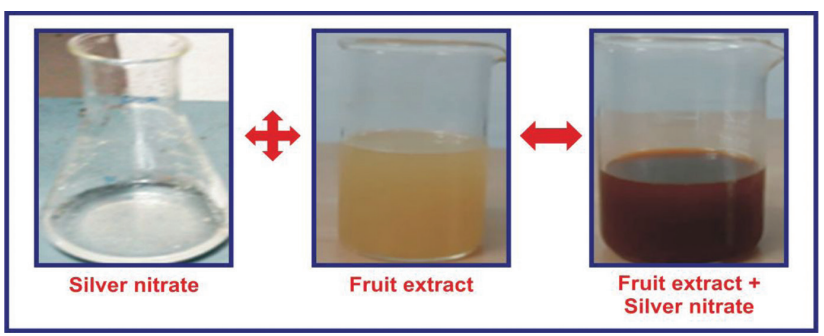

Figure 4: Synthesis of silver nanoparticles synthesis by Plum fruit extract. 
were observed to be stable even 2 months after synthesis. The particles were found to be suspended uniformly with no aggregation exhibiting the same absorption. Control experiments performed without the addition of plant extracts exhibits no transformation of color, demonstrating the color change was entirely due to the occurrence of plant extracts present in the silver nitrate solution [27].

\subsection{UV-Vis spectrophotometer analysis}

The reduction of silver nitrate into silver nanoparticles using the plant extract of $A$. bilimbi leaf and Plum fruit was observed by the change in color of the colloidal solution as shown in Figure 4. The absorbance spectra of Ag NPs at various time intervals were recorded using UV-vis spectrophotometer as in Figures 5a and 5b. In both the cases, the spectrum shows an intense peak at $450 \mathrm{~nm}$ for $A$. bilimbi and $405 \mathrm{~nm}$ for Plum fruit respectively with typical surface plasmon resonance (SPR) for Ag NPs. The SPR corresponds to the aggregation of conduction electrons in a metal. Also, the absorption spectrum of Ag NPs can be attributed to the property of Mie scattering resonance $[28,29]$.

\subsection{X-ray diffraction}

Analysis of physical structure and crystallite size of the phytochemical mediated synthesis of silver nanoparticles was determined from the using X-ray diffraction pattern (XRD). The typical XRD pattern of synthesized silver nanoparticles using a leaf extract of $A$. bilimbi and fruit extract of Plum is shown in Figures 6a and 6b, respectively. A. bilimbi leaf extract and Plum fruit mediated synthesis showed the same diffraction peaks at $2 \theta=32.04^{\circ}$, $35.67^{\circ}, 44.52^{\circ}, 61.65^{\circ}$, and $75.23^{\circ}$ corresponding to (104), (111), (200), (300) and (311) that can be assigned to face centered cubic symmetry of a silver crystal $[30,31]$. These characteristics were compared to standard powder diffraction card of Joint Committee on Powder Diffraction Standards that corroborated with JCPDS (No. 84-0713) [32]. The Debye-Scherer equation was used to calculate the crystallite size of AgNP as in Eq. 2:

$$
D=K \lambda / \beta \cos \theta
$$

where $D$ indicates the size of the NP, $K$ is a constant ranging from 0.9 to $1.0, \lambda$ is the X-ray wavelength (1.5418 $\AA$ ), $\beta$ is the line broadening at half the maximum intensity (FWHM); $\theta$ is the Bragg angle (in degrees) [33].

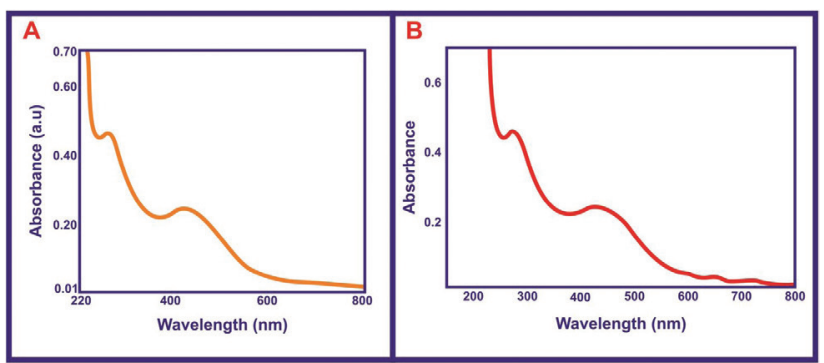

Figure 5: UV-Vis absorption spectra of Ag NPs of (a) A. bilimbi leaf and (b) Plum fruit.
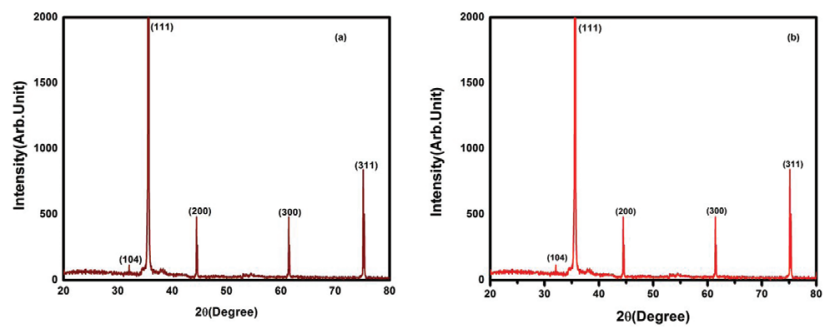

Figure 6: X-ray diffraction pattern of AgNPs (JCPDS No: 84-0713) of (a) A. bilimbi leaf and (b) Plum fruit.

The average size of the synthesized silver nanoparticles from a plant extract of $A$. bilimbi leaf and Plum fruit were found to be $29 \mathrm{~nm}$ and $47 \mathrm{~nm}$, respectively. Bragg's peaks get broaden around their bases shown in Figures $6 \mathrm{a}$ and $6 \mathrm{~b}$ indicating the formation of small sized silver nanoparticles [34]. These Bragg peaks might have resulted from bioorganic compounds/proteins present in the Plum fruit extract which crystallizes at the surface of the silver [35].

\subsection{Fourier transform infra-red spectroscopy}

The potential functional groups responsible for the biosynthesis of Ag NPs from leaf and fruit extract of $A$. bilimbi and Plum were identified by FTIR analyses shown in Figure 7a and 7c respectively in comparison with FTIR spectrum of AgNPs shown in Figure 7b. The phytochemical compounds behaved as a reducing and stabilizing agent as well in the synthesis [36]. The FTIR spectrum of silver nanoparticles synthesized using A. bilimbi leaf extract, Figure $7 \mathrm{a}$ shows the prominent absorption peaks at $3450 \mathrm{~cm}^{-1}, 2073 \mathrm{~cm}^{-1}, 1636 \mathrm{~cm}^{-1}$, and $648 \mathrm{~cm}^{-1}$ indicating the presence of $\mathrm{N}-\mathrm{H}$ asymmetric stretching attributing to Amides group, $\mathrm{C}=\mathrm{C}$ stretching vibration indicating Alkynes group, $\mathrm{N}-\mathrm{H}$ bend indicating the primary Amines group and C-Br stretching vibration indicating the Alkyl halides group. FTIR spectroscopic studies confirmed 


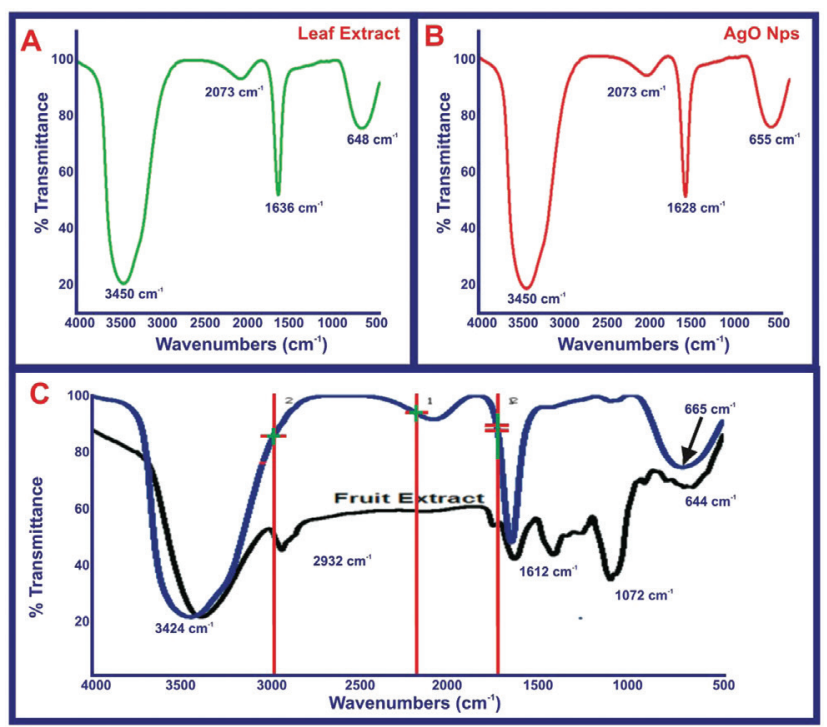

Figure 7: FTIR spectra of synthesized silver nanoparticles using (a) A. bilimbi leaf extract, (b) silver nanoparticle, (c) Plum fruit extract.

that a peak residing at $655 \mathrm{~cm}^{-1}$ specified strong binding affinities with the metal suggesting the encapsulation of metal nanoparticles. These results confirm the presence of possible proteins acting as reducing and stabilizing agents for Silver Nanoparticles [37]. The FTIR spectrum of AgNPs synthesized using Plum fruit extract is shown in Figure 7c. The Sharp absorption peak at $664 \mathrm{~cm}^{-1}$ can be attributed due to $\mathrm{C}-\mathrm{Cl}$ stretching for halogen compounds, the alcohol and phenols stretching of $\mathrm{C}-\mathrm{O}$ bond occur at $1072 \mathrm{~cm}^{-1}$, the band at $1612 \mathrm{~cm}^{-1}$ exist due to $\mathrm{C}=\mathrm{O}$ stretch of tertiary amides and the broad peak at $3424 \mathrm{~cm}^{-1}$ is the characteristic $\mathrm{O}-\mathrm{H}$ stretching for alcohols and phenols. Also, the carbonyl group present in amino acid debris and proteins showcase a stronger possibility to interact with metal for a possible capping, thereby avoiding agglomeration. Thus, biological molecules enforce the dual role of formation and stabilization of AgNPs in the aqueous medium [38].

\subsection{Field emission scanning electron microscope (FESEM)}

Surface Morphology, size, and shape of the synthesized silver nanoparticles by using plant extract of Averrhoa bilimbi leaf and Plum fruit analyzed by FESEM showed in Figure 8. Images of the silver nanoparticles synthesized by Averrhoa bilimbi leaf extract is shown in Figure 8a and $8 \mathrm{~b}$. The surface morphology of silver oxide nanoparticles showed even shape and spherical nature. In the present

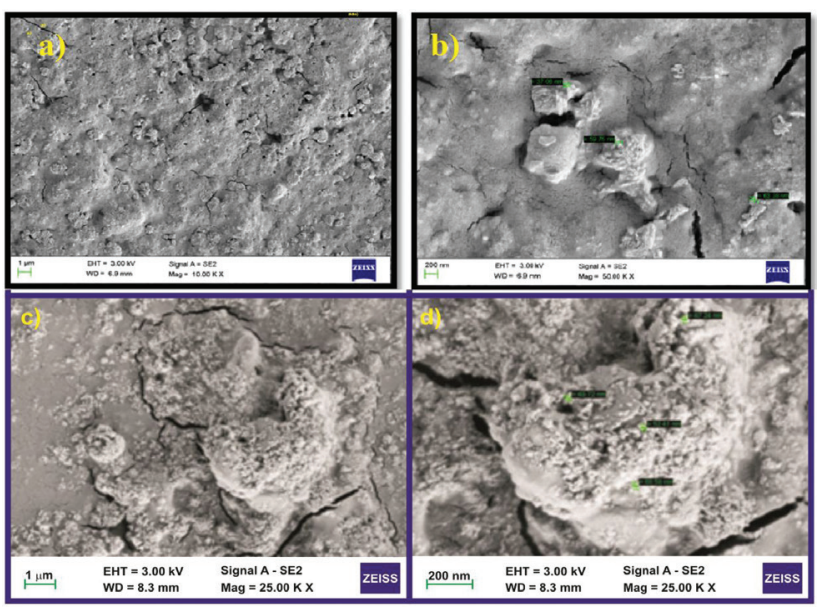

Figure 8: FESEM image of silver nanoparticles synthesized from Plum fruit extract.

study, the histogram of the particle size ranges from 20 to $50 \mathrm{~nm}$. Figure $8 \mathrm{c}$ and $8 \mathrm{~d}$ shows the FESEM images of the synthesized silver nanoparticles by using Plum fruit extract. From the figure, it is clear that spherical particles are predominating with an almost smooth surface that is closely packed. The average particle size was found around $47 \mathrm{~nm}$. The dimension observed here is approximately the same as the crystallite size as inferred by XRD. Thus, the outcomes strongly recommend that Averrhoa bilimbi leaf extract acts as a strong reducing and capping agent in the assembling of silver nanoparticles [39].

\subsection{Energy dispersive X-ray (EDS) analysis}

An X-ray EDS analysis was performed to authenticate the presence of AgNPs using A. bilimbi leaf and Plum fruit, shown in Figures 9a-d. Due to the existence of Surface Plasmon Resonance, typically strong resonance peak was observed at $3 \mathrm{keV}$ for AgNPs obtained from both extracts [40]. Also, weak peaks for Carbon and Oxygen was also reflected in the EDS analysis. The existence of the frail oxygen peak can be predicted due to the discharge of carbohydrates or protein enzymes present within the plant extracts during X-ray emission [41]. Since, the nanoparticles formed are highly reactive due to their elevated surface to volume ratio, during the reduction process the probability of formation of silver oxide nanoparticles is also evidence of its reactivity with an aqueous solution, which can be considered as one of the benefits of green synthesis of NPs over conventional methods [42]. In the current examination, the AgNPs confirms a stronger absorption in the range between 


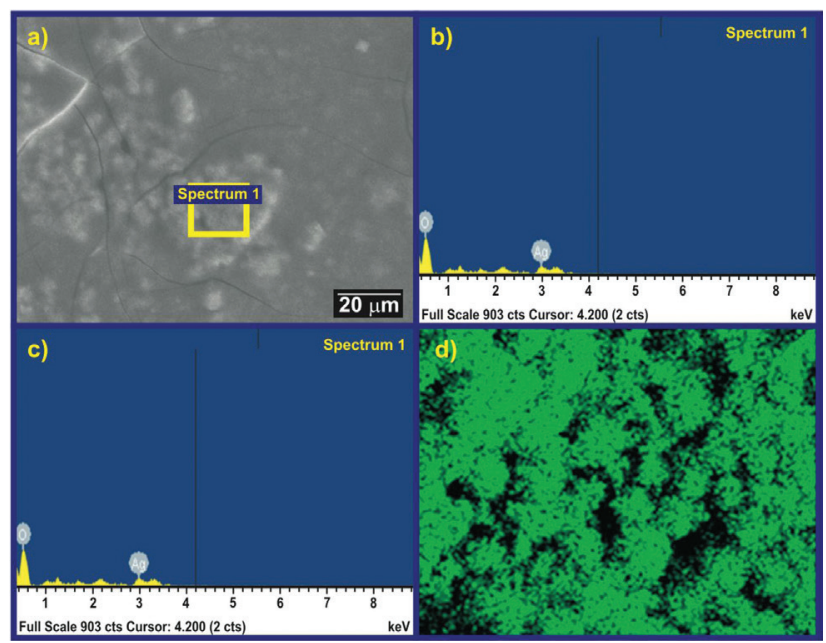

Figure 9: EDS image of synthesized silver nanoparticles from: $(a, b)$ Averroh bilimbi leaf extract, (c,d) Plum fruit extract.

Table 1: EDS Atomic percentage of formation of silver nanoparticles.

\begin{tabular}{lll}
\hline Element & Weight\% & Atomic\% \\
\hline O K & 42.02 & 83.01 \\
Ag L & 57.98 & 16.99 \\
Totals & 100.00 & \\
\hline
\end{tabular}

1.261 and $1.721 \mathrm{keV}$. The weight of the atomic percentage of the reduced AgNPs has been represented in Table 1.

\subsection{Dynamic light scattering (DLS) analysis}

DLS was used to investigate the particle size of the synthesized AgNPs by means of A. bilimbi leaf and Plum fruit extract. Figure 10a shows the DLS graph of A. bilimbi leaf and Plum fruit extract respectively. The polydispersity index (PDI) of particles in a colloidal suspension is determined by the graphs shown in Figures 10a and 10b. The mean size of silver nanoparticles synthesis by leaf extract at optimum condition was recorded $160 \mathrm{~nm}$ and the range of nanoparticles from 1.6 to $160 \mathrm{~nm}$. Figure $10 \mathrm{~b}$ displays the DLS chart of Plum fruit extract. Grounded on the observed results mean size of silver nanoparticles was recorded as $128 \mathrm{~nm}$ and spread in the range from 1.7 to $137 \mathrm{~nm}$. A for The PDI is a measurement of the dispersed silver nanoparticle was in the range from 0.001 to 0.5 if PDI is larger than 0.5 , it indicates the aggregation of particles [43]. Thus, the synthesized silver nanoparticle by Averroh bilimbi leaf and Plum fruit extracts does not aggregate. As predicted from FESEM and XRD studies, the
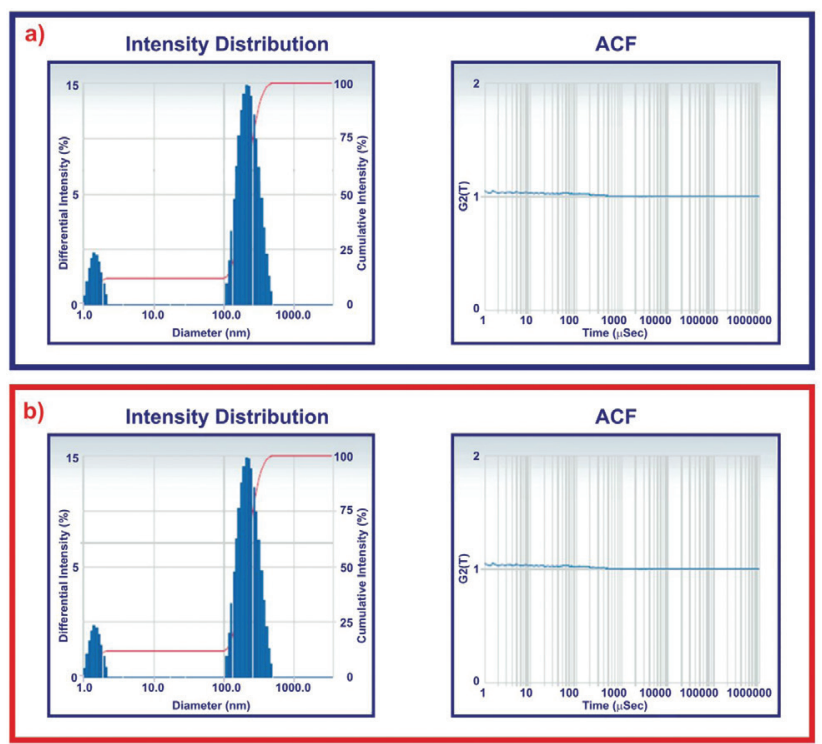

Figure 10: DLS analysis of synthesized silver nanoparticle obtained from: (a) Averrhoa bilimbi leaf extract, (b) Plum fruit extract.

DLS measured the size of the particles is somewhat bigger for both the extracts.

\subsection{Antimicrobial susceptibility testing-well diffusion assay}

The antibacterial activity of the Ag NPs synthesized using A. bilimbi leaf and Plum fruit extracts were determined by agar disk diffusion method against pathogenic bacteria such as Staphylococcus aureus, Escherichia coli, Pseudomonas aeruginosa, and Salmonella typhi. Ag NPs (synthesized from two different extracts) of concentrations 2, 4 and $6 \mathrm{mg} / \mathrm{mL}$ was prepared in MilliQ water and added to the wells of lawn cultured agar plates. The aqueous extract served as negative control and Amoxicillin antibiotic served as a positive control. The plates were incubated at $37^{\circ} \mathrm{C}$ for $18-24 \mathrm{~h}$ in a humidified chamber. The antimicrobial susceptibility of Ag NPs as shown in Figures 11 and 12 revealed significant inhibition in a concentrationdependent fashion against Escherichia coli, Staphylococcus aureus, Pseudomonas aeruginosa, and Salmonella typhi. There was a maximum inhibition in the growth of $S$. typhi with $70 \%, 77.5 \%$ and $85 \%$ inhibition at 2, 4 and $6 \mathrm{mg} / \mathrm{mL}$ concentrations. This was followed by P. aeruginosa with $66.6 \%, 71.4 \%$ and $78.5 \%$ and $E$. coli with $63.1 \%, 71 \%$ and $78.9 \%$ at given concentrations. These results agreed with the earlier reports on the susceptibility patterns [44]. On the other hand, the susceptibility pattern varied with Gram-positive bacterium viz. S. aureus with 57.8\%, 


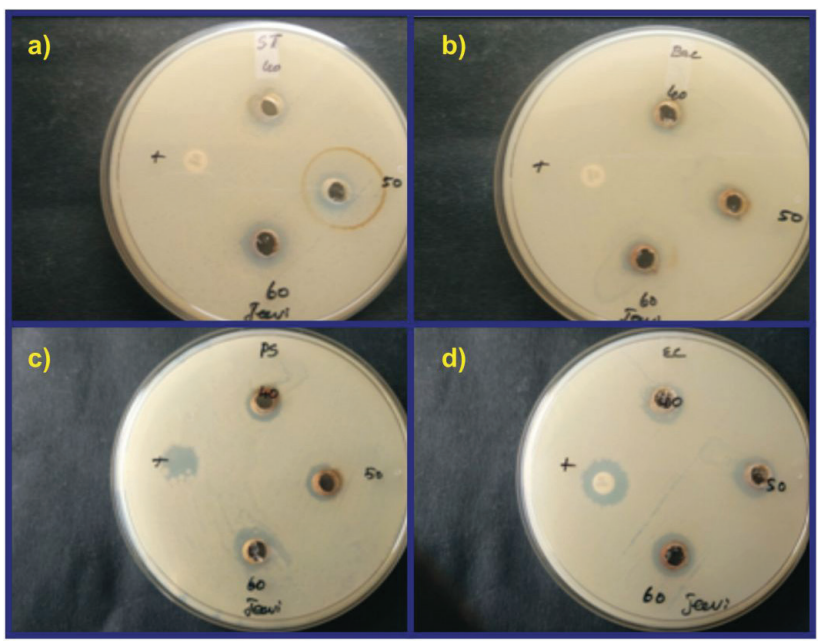

Figure 11: Antibacterial activity of $A$. bilimbi leaf extract mediated synthesized AgNPs: (a) Escherichia coli, (b) Staphylococcus aureus, (c) Pseudomonas aeruginosa and (d) Salmonella typhi.

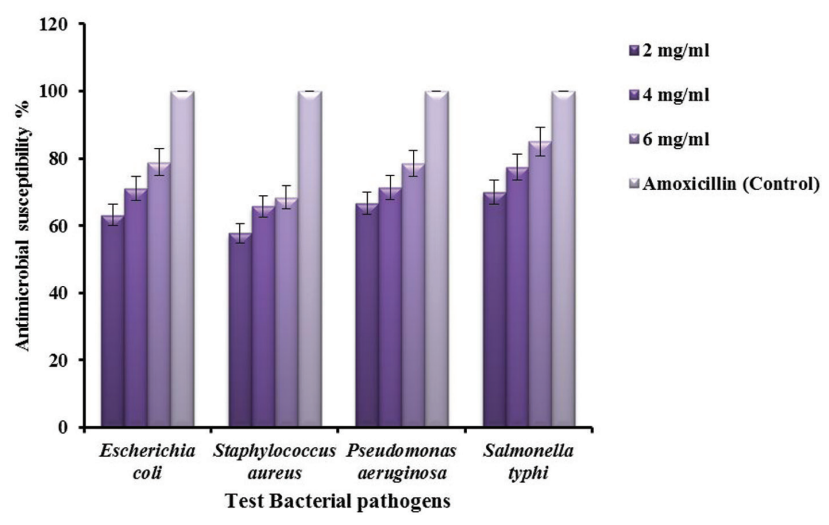

Figure 12: Antimicrobial activity of Ag NPs synthesized by A. bilimbi leaf extract represented in \%.

$65.7 \%, 68.4 \%$ at 2,4 and $6 \mathrm{mg} / \mathrm{mL}$ concentration of $\mathrm{Ag}$ NPs. Among the bacterial strains exposed, Gram-negative strains showed higher susceptibility towards Ag NPs as evidenced from the zone of inhibition which is mainly due to the discrepancy in the composition of cell wall exist between the gram positive and gram negative bacteria [27]. The difference in inhibition toward different strains was found to be statistically significant (ANOVA, $p<0.05$ ).

Similarly, the antimicrobial susceptibility of Ag NPs synthesized using Plum fruit extract was elaborated in Figures 13 and 14 revealing significant inhibition in a concentration-dependent fashion against the test cultures. There was a maximum inhibition in the growth of S. typhi with $75 \%, 82.5 \%$ and $90 \%$ inhibition at 2, 4 and $6 \mathrm{mg} / \mathrm{mL}$ concentrations. This was followed by $P$. aeruginosa with $71.4 \%, 78.6 \%, 85.7 \%$ and $E$. coli with $68.4 \%, 76.3 \%$ and $84.2 \%$ at all concentrations. The susceptibility pattern

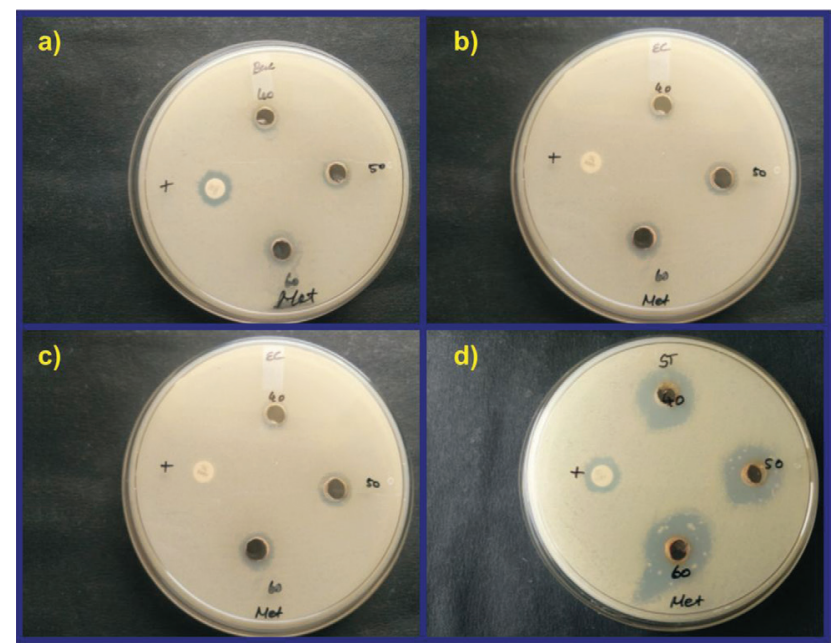

Figure 13: Antibacterial activity of Plum fruit extract mediated synthesized AgNPs: (a) Escherichia coli, (b) Staphylococcus aureus, (c) Pseudomonas aeruginosa and (d) Salmonella typhi.

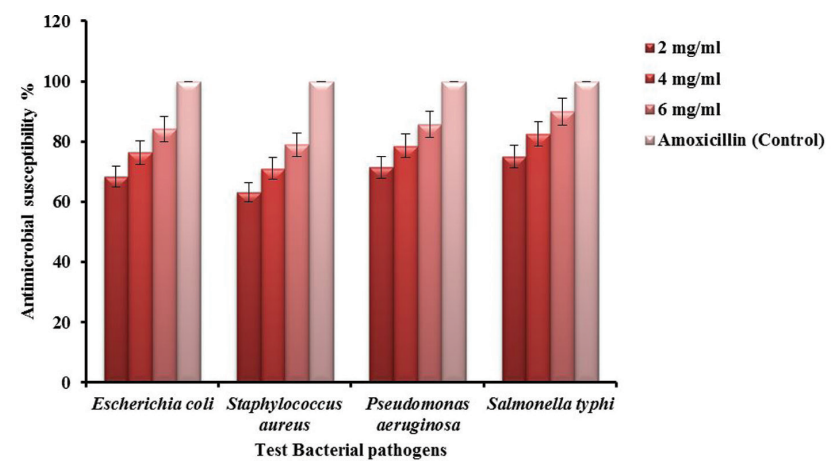

Figure 14: Antimicrobial susceptibility of Ag NPs synthesized by Plum fruit extract represented in \%.

followed the same trend as A. bilimbi leaf toward Grampositive $S$. aureus with $63.2 \%, 71.1 \%$ and $78.9 \%$ at 2,4 and $6 \mathrm{mg} / \mathrm{mL}$ concentrations [45]. Moreover, statistical analysis across different groups of test organisms exposed to different doses was found significant (ANOVA, $p<0.05$ )

This severity might have resulted due to the membranous architecture present in Gram-negative strains. The absence of thick peptidoglycan in Gram-negative strains might have paved way for nanoparticles intrusion and ionization pertinent to severe damage in the cell membrane. On the other hand, the presence of peptidoglycan in Grampositive strain could have trapped most of the nanoparticles thereby preventing the cells from damage [46]. The nanoparticles preferably attack the respiratory chain and cell division finally leading to cell death.

The synthesized Ag NPs using A. bilimbi leaf and Plum fruit extracts shows highest antibacterial activity against S. typhi followed by P. aeruginosa in both the cases. 
Moreover, the synthesized AgNPs enhance the remedial adequacy of both the extracts when consolidating with silver.

\subsection{In vitro cytotoxicity study of Vero and HEp-2 cells}

The anti-proliferative activity of phytochemical mediated synthesis of Ag NPs was investigated for their cytotoxicity in Vero and Human epidermoid larynx carcinoma cell lines (HEp-2) based on their viability using MTT assay. As shown in Figure 15, Vero and HEp-2 cells exposed to Ag NPs were read after $24 \mathrm{~h}$ of treatment. There was a significant cytotoxic effect in a concentration-dependent manner. The estimated half maximal inhibitory concentration $\left(\mathrm{IC}_{50}\right.$ ) for A. bilimbi mediated Ag NPs exposed to Vero and HEp-2 cells was determined to be $76.9 \mu \mathrm{g} / \mathrm{mL}$ and $49.49 \mu \mathrm{g} / \mathrm{mL}$ respectively. Similarly, the $\mathrm{IC}_{50}$ for Plum fruit extract mediated Ag NPs exposed worked out to $74.4 \mu \mathrm{g} / \mathrm{mL}$ and $62.5 \mu \mathrm{g} / \mathrm{mL}$ for Vero and HEp-2 cells respectively. The estimated MIC values carry critical consequence as low MIC indicates well-built bioefficacy of the extracts [47]. The MIC result showed that increasing concentration has increased efficiency in inhibiting the organisms used. Since more MIC values of Plum fruit extract indicate its more discrete nature of the antimicrobial activities as compared to A. bilimbi.

The cytotoxic effects were characterized from rounding of cells, clumping up of cells and non-adherence to the well surface at higher concentrations as in Figure 16. The increased cytotoxicity toward HEp-2 cells (carcinoma cells) was induced by Ag NPS synthesized using $A$. bilimbi leaf extract. This probably suggests the role of phytochemical compounds such as phenols, triterpenoids, and flavonoids acting synergistically with the nanoparticles in the event of inducing cytotoxicity. Alongside, there was also an enhancement in the diffusion of nanoparticles into the cell membrane by the greater intracellular uptake of the positively charged Ag NPs with non-specific interaction with the negatively charged cell membrane.

The detected $\mathrm{IC}_{50}$ value for $A$. bilimbi mediated $\mathrm{Ag}$ NPs exposed to Vero and HEp-2 cells was determined to be $76.9 \mu \mathrm{g} / \mathrm{mL}$ and $49.49 \mu \mathrm{g} / \mathrm{mL}$ respectively. $\mathrm{IC}_{50}$ for Plum fruit extract mediated Ag NPs exposed worked out to $74.4 \mu \mathrm{g} / \mathrm{mL}$ and $62.5 \mu \mathrm{g} / \mathrm{mL}$ for Vero and HEp-2 cells. Data are expressed as Mean \pm SD of three experiments. Percentage of cytotoxicity relative to controls $\left({ }^{*} p<0.05\right)$.

The transport of Ag NPs inside the cell begins with receptor recognition, internalization, and translocation. Once the Ag NPs were in-taken via endocytosis, the major
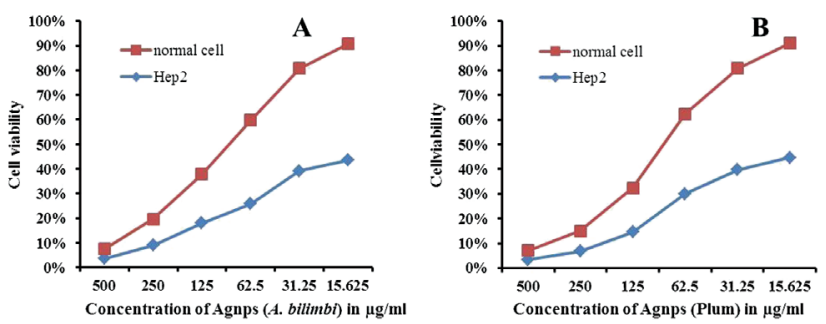

Figure 15: Cytotoxicity studies on Vero and HEp2 cells exposed to Ag NPs synthesized using (a) A. bilimbi leaf extract and (b) Plum fruit extract.
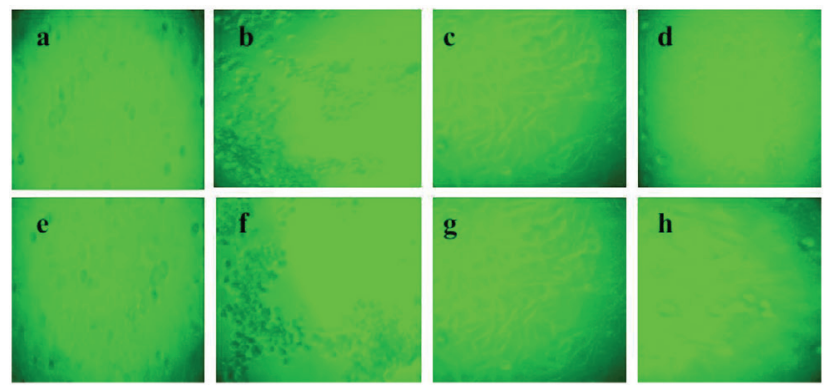

Figure 16: Micrograph of cytotoxicity induced by Ag NPs on Vero and HEp2 cells. Vero: control (a,e), IC50 of A. bilimbi Ag NPs (b) and IC50 of Plum Ag NPs (f). HEp2: control (c,g), IC50 of A. bilimbi Agnps (d) and IC50 of Plum Ag NPs (h).

target organelles were endosomes and lysosomes [48]. Internalized Ag NPs were found in mitochondria and the nucleus. Once internalized, these Ag NPs induce a series of effects including oxidative stress, impairment of the cell membrane, cell cycle arrest, inflammatory responses, DNA damage and genotoxicity, chromosome aberration and apoptosis [49]. Moreover, these Ag NPs have the capacity to produce ROS and oxidative stress by themselves imparting toxic effects on the cells thereby influencing cellular responses [50].

\section{Conclusion}

Cost-effective, safe, non-toxic, economical and environmentally friendly silver nanoparticles (Ag NPs) were successfully synthesized using the leaf and fruit extract of A. bilimbi and Plum plant. Phytochemical moieties present in the leaf and fruit extracts played a major role as a reducing and capping agent. Biosynthesis of silver oxide nanoparticle was firstly visible confirmed by the change in color of the solution from pale green to dark brown. The surface plasmon vibrations present in silver nanoparticles responsible for the yellowish brown color in water which is further confirmed by UV-Vis Spectrophotometer Analysis shows sharp bands 
obtained at the peak range of $450 \mathrm{~nm}$ and $405 \mathrm{~nm}$ of synthesized silver nanoparticles from extracts of $A$. bilimbi leaf and Plum fruit respect. The XRD patterns confirmed the purity, face-centered cubic and crystalline nature of the synthesized silver nanoparticles by using $A$. bilimbi leaf and Plum fruit extracts with size ranging between $29 \mathrm{~nm}$ and $47 \mathrm{~nm}$, respectively. FTIR analysis unraveled the presence of phytochemical moieties involved in the reduction process and capping agent as well as present in the extract solution. FESEM and EDS analysis were helpful at deciphering their morphology spherical in shape and stable were also in full agreement with the XRD results obtained. The particle size distribution recorded for silver nanoparticles by DLS analysis in the range from 1.6 to $160 \mathrm{~nm}$ and 1.7 to $137 \mathrm{~nm}$ for Averrhoa bilimbi leaf and Plum fruit resp.

Ag NPs synthesized using leaf extract of $A$. bilimbi showed significant antibacterial activity against the tested pathogens than Plum fruit extract. Gram-negative strains sustained severe damage than Gram-positive strains due to the membranous architecture. Alongside, Ag NPs synthesized using leaf extract of $A$. bilimbi showed significant cytotoxicity toward HEp-2 cells with an $\mathrm{IC}_{50}$ value of $49.49 \mu \mathrm{g} / \mathrm{mL}$ on a par with Vero cells. This synergistic antimicrobial and cytotoxic effect induced by plant-mediated synthesis protocol might open new vistas in the field of nanomedicine once the level of toxicity in vivo is validated.

Competing interests: The authors declare no conflict of interest.

Acknowledgments: The author would like to acknowledge the financial support provided by Research University grant number (RU001-2018) NANOCAT, University of Malaya, Malaysia. One of the authors (Suresh Sagadevan) acknowledges the honor, namely the "Senior Research Fellow" at Nanotechnology \& Catalysis Research Centre (NANOCAT), University of Malaya 50603 Kuala Lumpur, Malaysia. The author wishes to place on record his heartfelt thanks that are due to the authorities concerned.

\section{References}

[1] Ansari M.A., Khan H.M., Khan A.A., Cameotra S.S., Pal R., Antibiofilm efficacy of silver nanoparticles against biofilm of extended spectrum b-lactamase isolates of Escherichia coli and Klebsiella pneumoniae. Appl. Nanosci, 2013, 7, 859-868.

[2] Jyothi A., Manjunath C., Chandrakanth R.K., Prevention of multiple drug resistant bacterial biofilm by synergistic action of biogenic silver nanoparticle and antimicrobials. J. Microbial. Biotech. Res., 2015, 5, 14-21.

[3] Donlan R.M., Biofilms and device-associated infections. Emerg. Infect. Dis., 2001, 7, 277-281.

[4] Markowska K., Grudniak A., Wolska K., Silver nanoparticle as an alternative strategy against bacterial biofilms. Acta Biochimi. Pol., 2013, 60, 523-530.

[5] Satish S., Raghavendra M.P., Raveesha K.A., Evaluation of the Antibacterial Potential of Some Plants Against Human Pathogenic Bacteria. Advances in Biological Research, 2008, 2(3-4), 44-48.

[6] Shet A.R., Ghose P., Patil L., Hombalimath V., A preliminary study on green synthesis and antibacterial activity of silver nanoparticles. Int. J. Curr. Biotechnol., 2015, 3, 1-6.

[7] Nagajyothi P.C., Lee K.D., Synthesis of Plant-Mediated Silver Nanoparticles Using Dioscorea batatas Rhizome Extract and Evaluation of Their Antimicrobial Activities. J. Nanomater., 2011, 573429, 1-7.

[8] Ahmad N., Sharma S., Singh V.N., Shamsi S.F., Fatma A., Mehta B.R., Biosynthesis of Silver Nanoparticles from Desmodium triflorum: A novel approach towards weed utilization. Biotechnol. Res. Inter., 2011, 454090, 1-8.

[9] Kulkarni N., Muddapur U., Biosynthesis of Metal Nanoparticles: A Review. J. Nanotechnol., 2014, 510246, 1-8.

[10] Kumar B., Naik V., Halehatty S.B., Girija D., Kumar B.V., ZnO nanoparticle as catalyst for efficient green one-pot synthesis of coumarins through Knoevenagel condensation. J. Chem. Sci., 2011, 123, 615-621.

[11] Soloviev M., Nanobiotechnology today: focus on nanoparticles. J. Nanobiotechnol., 2007, 5, 1-11.

[12] Pramila M., Meenakshisundaram M., Biosynthesis of Iron (Fe) Nanoparticles And Its Inhibitory Effect On Pseudomonas Aeruginosa Biofilm. Indian J. App. Res., 2017, 7, 251-524.

[13] Das R.K., Pachapur V.L., Lonappa L., Naghdi M., Pulicharla R., Maiti S., et al., Biological synthesis of metallic nanoparticles: plants, animals and microbial aspects. Nanotechnol. Environ. Eng., 2017, 18, 1-21.

[14] Nair R., Varghese S.H., Nair B.G., Maekawa T., Yoshida Y., Kumar S.D., Nanoparticulate material delivery to plants. Plant Sci., 2010, 179, 154-163.

[15] Wildenberg V.D., Roadmap report on nanoparticles. W\&W Espana sl, Barcelona, Spain, 2005.

[16] Quang H.T., Van Q.N., Anh-Tuan L., Silver nanoparticles: synthesis, properties, toxicology, applications and perspectives. Adv. Nat. Sci. Nanosci. Nanotechnol., 2013, 4, 1-20.

[17] Khalil K.A., Fouad H., Elsarnagawy T., Almajhdi F.N., Preparation and characterization of electrospun PLGA/silver composite nanofibers for biomedical applications. Inter. J. Electrochem. Sci., 2013, 8, 3483-3493.

[18] Ahmad A., Mukherjee P., Senapati S., Extracellular biosynthesis of silver nanoparticles using the fungus Fusarium oxysporum. Colloid. Surface. B, 2003, 28, 313-318. 
[19] Nakkala J.R., Mata R., Gupta A.K., Sadras S.R., Biological activities of green silver nanoparticles synthesized with Acorous calamus rhizome extract. Eur. J. Med. Chem., 2014, 8, 784-794.

[20] Nabikhan A., Kandasamy K., Raj A., Alikunhi N.M., Synthesis of antimicrobial silver nanoparticles by callus and leaf extracts from saltmarsh plant Sesuvium portulacastrum L, Colloid. Surface. B, 2010, 79, 488-493.

[21] Ulug B., Turkdemir M.H., Cicek A., Mete A., Role of irradiation in the green synthesis of silver nanoparticles. Spectrochim. Acta A, 2015, 135, 153-161.

[22] Isaac R.S.R., Sakthivel G., Murthy C.H., Green Synthesis of Gold and Silver Nanoparticles Using Averrhoa bilimbi Fruit Extract. J. Nanotechnol., 2013, 906592, 1-6.

[23] Singh K., Panghal M., Kadyan S., Yadav J.P., Green silver nanoparticles of Phyllanthus amarus: as an antibacterial agent against multi drug resistant clinical isolates of Pseudomonas aeruginosa. J. Nanobiotechnol., 2014, 12(40), 1-9.

[24] Veeraputhiran V., Bio-Catalytic synthesis of silver nanoparticles. Inter. J. Chemtech. Res., 2013, 5, 2555-2562.

[25] Sadeghi B., Rostami A., Momeni S.S., Facile green synthesis of silver nanoparticles using seed aqueous extract of Pistacia atlantica and its antibacterial activity. Spectrochim. Acta A, 2015, 134, 326-332.

[26] Roy K., Biswas S., Banerjee P.C., Green synthesis of silver nanoparticles by using grape (Vitis vinifera) fruit extract: Characterization of the particles and study of antibacterial activity. Res. J. Pharma. Bio. Chem. Sci., 2013, 4, 1271-1278.

[27] Jemal K., Sandeep B.V., Pola S., Synthesis, Characterization, and Evaluation of the Antibacterial Activity of Allophylus serratus Leaf and Leaf Derived Callus Extracts Mediated Silver Nanoparticle. J. Nanomater., 2017, 4213275, 1-11.

[28] Sileikaite A., Prosycevas I., Puiso J., Juraitis A., Guobiene A., Analysis of Silver Nanoparticles Produced by Chemical Reduction of Silver Salt Solution. Mat. Sci., 2006, 12, 287-291.

[29] Aoki K., Chen J., Yang N., Nagasaga H., Charge-Transfer Reactions of Silver Stearate-Coated Nanoparticles in Suspensions. Langmuir, 2003, 19, 9904-9909.

[30] Roy K., Sarkar C.K., Ghosh C.K., Plant-mediated synthesis of silver nanoparticles using parsley (Petroselinum crispum) leaf extract: spectral analysis of the particles and antibacterial study. App. Nanosci., 2015, 5, 945-951.

[31] Chandrasekaran C.V., Sundarajan K., Edwin J.R., Gururaja G.M., Mundkinajeddu D., Agarwal A., Immune-stimulatory and anti-inflammatory activities of Curcuma longa extract and its polysaccharide fraction. Pharmacogn. Res., 2013, 5, 71-79.

[32] Elumalai D., Hemavathi M., Deepa C.V., Kaleen P.K., Evaluation of photosynthesized silver nanoparticles from leaf extracts of Leucas aspera and Hyptis suaveolens and their larvicidal activity against malaria, dengue and filariasis vectors. Parasite Epidemiol. Control, 2017, 18, 15-26.
[33] Pradeev raj K., Sadaiyandi K., Kennedy A., Sagadevan S., Chowdhury Z.Z., Bin Johan M.R., et al., Influence of Mg Doping on ZnO Nanoparticles for Enhanced Photocatalytic Evaluation and Antibacterial Analysis. Nanoscale Res. Lett., 2018, 13, 229.

[34] Annadurai G., Gnana Jobith G., Rajeshkumar S., Kannan C., Preparation and characterization of fruit-mediated silver nanoparticles using pomegranate extract and assessment of its antimicrobial activities. J. Env. Nanotechnol., 2013, 2, 4-10.

[35] Philip D., Mangifera indica leaf-assisted biosynthesis of well dispersed silver nanoparticles. Spectrochim. Acta A., 2011, 78, 327-331.

[36] Jesús A.D., Baltazar R., Yobbany S., Lopez R., Larranaga D., Estevez M., et al., Green synthesis of silver nanoparticles using a Melissa officinalis leaf extract with antibacterial properties. Results Phys., 2017, 7, 2639-2643.

[37] Huang Q., Li D., Sun Y., Lu Y., Su X., Yang H., et al., Biosynthesis of silver and gold nanoparticles by novel sundried Cinnamomum camphora leaf. Nanotechnol., 2007, 18, 105104.

[38] Selvaraj V., Sagadevan S., Muthukrishnan L., Johan M.R., Podder J., Eco-friendly approach in synthesis of silver nanoparticles and evaluation of optical, surface morphological and antimicrobial properties. J. Nan. Chem., 2019, DOI:10.1007/s40097-019. 0306-9.

[39] Banerjee P., Satapathy M., Mukhopahayay A., Das P., Leaf extract mediated green synthesis of silver nanoparticles from widely available Indian plants: synthesis, characterization, antimicrobial property and toxicity analysis. Bioresources and Bioprocessing, 2014, 1, 1-10.

[40] Bindhu M.R., Umadevi M., Synthesis of monodispersed silver nanoparticles using Hibiscus cannabinus leaf extract and its antimicrobial activity. Spectrochim. Acta A, 2013, 101, 184-190.

[41] Vanaja M., Annadurai G., Coleus aromaticus leaf extract mediated synthesis of silver nanoparticles and its bactericidal activity. App. Nanosci., 2013, 3, 217-223.

[42] Singha S., Neog K., Kalita P.P., Talukdar N., Sarma M.P., Biological synthesis of silver nanoparticles by Neptunia oleraceae. Inter. J. Basic App. Bio., 2014, 2, 55-59.

[43] Singh K., Panghal M., Kadyan S., Yadav J.P., Evaluation of Antimicrobial Activity of Synthesized Silver Nanoparticles using Phyllanthus amarus and Tinospora cordifolia Medicinal Plants. Nanomed. Nanotechnol., 2014, 5, 1-5.

[44] Namratha N., Monica P.V., Synthesis of silver nanoparticles using Azadirachta indica (Neem) extract and usage in water purification. Asian J. Pharm. Tech., 2013, 3, 170-174.

[45] Logeswari P., Silambarasan S., Abraham J., Synthesis of silver nanoparticles using plants extract and analysis of their antimicrobial property. J. Saudi Chem. Soc., 2015, 19, 311-317.

[46] Sondi I., Salopek-Sondi B., Silver nanoparticles as antimicrobial agent: a case study on $E$. coli as a model for Gram-negative bacteria. J. Colloid. Interface. Sci., 2004, 275, 177-182. 
[47] Sharma J., Kumar P., Comparative Study of Antimicrobial Activity and Phytochemical Screening of Serial Extracts From Leaves And Fruit of Aegle Marmelos and Carica Papaya. Inter. J. Pharm. Pharm. Sci., 2017, 9, 119-123.

[48] Asharani P.V., Hande M.P., Valiyaveettil S., Anti-proliferative activity of silver nanoparticles. BMC Cell Biol., 2009, 10, 65-69.
[49] Kim Y.J., Yang S.I., Ryu J.C., Cytotoxicity and genotoxicity of nano-silver in mammalian cell lines. Mol. Cell Toxicol., 2010, 6, 119-125.

[50] Kawata K., Osawa M., Okabe S., In vitro toxicity of silver nanoparticles at noncytotoxic doses to HepG2 human hepatoma cells. Environ. Sci. Technol., 2009, 43, 6046-6051. 